\title{
General Business Competencies Of Students As Outcomes Assessment
}

\author{
Kathryn J. Ready, (E-mail: kready@winona.edu), Winona State University \\ Milorad M. Novicevic, (E-mail: mnovicevic@bus.olemiss.edu), University of Mississippi \\ Abdulaziz Elfessi, (elfessi.abdu@uwlax.edu), University of Wisconsin - La Crosse \\ Thomas Kuffel, (kuffel.thom@uwlax.edu), University of Wisconsin -- La Crosse
}

\begin{abstract}
The purpose of this paper is to develop an analytical framework to assess students' general business competencies, acquired in core and capstone courses, as learning outcomes. First, the rationale for the use of students' general business competencies as outcomes assessment is provided. Second, the methodology for measuring these competencies is presented and explained. Third, the underlying concepts and influential factors relative to general business competencies of students are analyzed and discussed. Finally, the findings and practical implications of the proposed approach for faculty development are examined.
\end{abstract}

\section{INTRODUCTION}

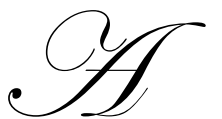

t the onset of the $21^{\text {st }}$ century, the need to emphasize general business competencies (i.e. GBCs) in the business school curricula is growing as the rate of knowledge development in the economy has rapidly increased (Stover et al., 1997; Novicevic, Harvey, Buckley \& Elfessi, 2002). The need is further accentuated as knowledge about cross-functional and competitive business practices is created and disseminated by many sources other than universities (i.e., corporate, private and governmental sources) (Atkinson, 2001). This accelerating trend evolves, however, at the time when budget constraints reduce the capacity of business schools to deliver the expected quality of educational service. In addition, the delivery of such integration at the instructional level becomes complex as the traditional modes of teaching and assessment are being challenged by the variety of the ever-changing content accessible through the Web (Donnelly and Fitzmaurice, 2005; Phar, 2000). As a result of the growing demand and constrained delivery of business knowledge integration, it has become critical for a business school to identify the core GBCs of career-minded students that they perceive to acquire as learning outcomes in the business program in general and the strategy/capstone course in particular (Entwistle, 2005; Glaser, 1990; Apostolou, 1999).

The purpose of this paper is to develop an analytical framework to assess students' general business competencies as learning outcomes of a strategy/capstone course. First, the rationale for the use of students' general business competencies as outcomes assessment is provided. Second, the methodology for measuring these competencies is presented and explained. Third, the underlying concepts and influential factors relative to general business competencies of students are analyzed and discussed. Finally, the findings and practical implications of the proposed approach for faculty development are examined.

As the complexity of delivering an up-to-date strategy/capstone course within the business program increases, an additional serious pressure is imposed on business schools by the accrediting institutions and the recruiting companies for the policy change relative to the integration of business school curricula. Specifically, business schools are expected to create innovative programs intended to provide competency-based degrees in which the integration between core courses and the strategy course can be demonstrated. While administrators often emphasize the potential benefits of such programs (i.e. achievement of economies of scale in servicing multiple student segments and fostering educational innovations), they seldom examine and recommend the feasible means of implementing these new learning options within the existing program (Carlile and Jordan, 2005; Heady \& Smith, 2000; Hartenian, Schellinger \& Frederickson, 2001). Understandably, this administrative hesitation is natural as the 
competency-driven curriculum in a business school entails the thorny issues of appropriate outcomes assessment and the challenging unbundling of student GBCs not only across the business program in general but also at the boundary between the core courses and the capstone course in particular (Carini et al, 2006; de Russy, 1996).

\section{RATIONALE FOR USING GENERAL BUSINESS COMPETENCIES OF STUDENTS AS ASSESSMENT OUTCOMES}

In general, assessment of student GBCs involves evaluation of student learning outcomes beyond the mere grading of the students' learning experience (Mitchell, 2006; Michlitsch and Sidle, 2002). The underlying rationale posits that the maximization of student GBCs over the core and capstone courses is the central orientation in achieving effective learning outcomes because it benefits all stakeholders of a business school. The measurement of student GBCs as a learning outcome is, however, difficult due to multiple intermediate impacts and the multidimensional nature of this construct. The difficulty of capturing student GBCs objectively, along with the prohibitive cost of longitudinal standardized competency-based testing, often leads to the use of students' self-report of learning experiences and competency development, which serve as proxies for the business program's quality (Phar et al., 1997).

Past uses of perceptual measures have been mostly focused on providing a macro-perspective on outcomes assessment that crosses business disciplines. In particular, general education aspects have been emphasized over professional education aspects by accentuating personal and social growth as well as critical thinking variables (Graham \& Cockreid, 1997). In contrast, this study accentuates educational effects of developing professional competencies and internalizing integrated business content to identify the weaknesses in the curriculum so that appropriate adjustments could be made relative to the core and capstone courses (i.e. more integration and faculty development in specific content/topic areas).

The method proposed in this paper employs the measurement of student perceptions of acquired competencies reflecting their integrated business knowledge before and after taking a strategy/capstone course as the focal course of business knowledge integration in the school's program. In particular, this paper focuses on using the "before and after" analysis to assess students' perceptions of how well they have acquired competencies across various concepts and tasks that are crucial to demonstrate integrated business knowledge. Students' perceptions are emphasized in this study because: 1) students are often singled out as the key stakeholders in mission statements of most business schools (Novicevic \& Buckley, 2001); 2) students' perceptions of how a college's services meet/satisfy their educational needs become critical for the institution's viability as competition for educational services increases (Chronicle, 1998); and, 3) the students who have just completed the strategy/capstone course are thought to be in the best position to assess the job/career market demands and their ability to meet such demands (Wren, Buckley and Michaelson, 1994).

Grounded in students' perceptions, the information captured by applying the proposed method can be used not only as a practical means of identifying and assessing strategy/capstone teaching effectiveness, but also as a unique input to the college's overall program assessment and curriculum planning and development. Moreover, the proposed analysis provides valuable and actionable results for faculty development.

\section{RESEARCH METHODOLOGY}

The methodology employed in this study follows the approach used extensively in research studies examining the effectiveness of service delivery (Remenyi \& Money, 1991). The approach consists of measuring students' perceptions of acquired integrative business competencies before taking and upon completing a strategy/capstone course. It offers useful insights while retaining the ease of calculation/interpretation that is crucial for practical implications of assessment findings. Within this framework, a convenient and simple approach to measurement is to use a 5-point interval scale (Brown \& Swartz, 1989). The use of this scale to measure student perceptions differentially offers a "gap-based" analysis, which is generally regarded as useful and powerful (Slack, 1994). 
This study, conducted in a mid-western AASB-accredited university at the end of a spring semester, involved data collection through a questionnaire distributed to graduating seniors in four sections of a strategy/capstone course taught by two faculty members (i.e. in order to mitigate possible instructor-specific effects). In the questionnaire, students were asked to rate (on a 5-point scale) their competencies related to integrated business functioning that they acquired before and after taking the strategic management course. Results were obtained from 162 respondents/students (i.e. 87 male and 75 female) of ages ranging mostly between 20 and 25 years (95.1\%). The shares of student majors were: finance (28\%), marketing (23.6\%), management (22.4\%), information systems (13.7\%), accounting (6.2\%), and economics (5.6\%). A consensus on the total of 24 specific student competencies for integrated business functions was reached by the strategy faculty upon extensive discussions held at the sessions of the Undergraduate Curriculum Committee. The means for both "before" and "after" measurements were calculated for each of 24 specific business competency items and are shown in Table 1 (see Table 1). In addition, for each of the 24 items, the mean competency-gap score and standard deviation are given, where the gap is determined by subtracting the "before" from "after" measurements to determine the marginal contribution of the strategy course regarding student learning relative to each specific competency.

Table 1: Means For Each Specific Student Competency Before And After Taking Strategy Class

\begin{tabular}{|c|c|c|c|}
\hline Factor 1: GBC to Interpret Macro Environment & $\begin{array}{c}\text { Mean } \\
\text { Before }\end{array}$ & $\begin{array}{l}\text { Mean } \\
\text { After }\end{array}$ & Gap \\
\hline $\begin{array}{l}\text { 12/Engage in lifelong learning about different aspects of business to remain current in the } \\
\text { profession. }\end{array}$ & 3.06 & 4.04 & .98 \\
\hline 5/Analyze the general environment, the industry and the competitors of a firm & 2.83 & 4.10 & 1.49 \\
\hline 7/Communicate effectively various business topics from multiple functional perspectives & 2.97 & 4.19 & 1.22 \\
\hline 20/Explain how various aspects of globalization affects a firm & 2.98 & 3.88 & .90 \\
\hline 21/Explain how efficiency can be achieved by integrating two or more business functions & 2.90 & 3.94 & 1.04 \\
\hline $\begin{array}{l}\text { 22/Explain how quality and innovation are dependent on the successful integration of different } \\
\text { business functions on the firm }\end{array}$ & 2.89 & 4.00 & 1.11 \\
\hline \multicolumn{4}{|l|}{ Factor 2: GBC to Communicate Alternatives and Data } \\
\hline 9/Develop strategic alternatives for a business firm using multiple sources of business data & 2.72 & 4.14 & 1.42 \\
\hline 11/Explain the advantages and disadvantages of your recommendation & 3.09 & 4.31 & 1.22 \\
\hline $\begin{array}{l}\text { 10/Recommend a choice of strategy for a business firm and present your recommendations } \\
\text { using the findings from your analysis }\end{array}$ & 2.67 & 4.38 & 1.71 \\
\hline $\begin{array}{l}\text { 23/”Sell” integrated business ideas or develop solutions by effective oral presentations and } \\
\text { written reports }\end{array}$ & 3.05 & 4.24 & 1.19 \\
\hline 17/Use the Web and other software packages for business analysis & 3.79 & 4.25 & 0.46 \\
\hline \multicolumn{4}{|l|}{ Factor 3: GBC for Planning and analysis } \\
\hline $\begin{array}{l}\text { 19/Analyze a firm's performance using labor, environmental, ethical and human rights measures } \\
\text { of performance }\end{array}$ & 2.97 & 3.81 & 0.84 \\
\hline $\begin{array}{l}\text { 24/Effectively plan work, set goals, stay on task and complete objectives on time, on budget, } \\
\text { and on objective. }\end{array}$ & 3.69 & 4.42 & 0.73 \\
\hline 15/Plan and execute complex team projects using different project management tools & 3.43 & 4.23 & 0.80 \\
\hline 16/Develop a business plan for a firm emphasizing customer focus & 2.98 & 3.89 & 0.90 \\
\hline \multicolumn{4}{|l|}{ Factor 4: GBC to Analyze hard data and Assess Economic Impact } \\
\hline 13/Use modern tools of business decision making, including capital budgeting and risk analysis & 2.87 & 3.48 & 0.61 \\
\hline 18/Analyze a firm’s performance using accounting and economic measures & 3.20 & 3.66 & 0.46 \\
\hline 14/Interpret contemporary business issues from different stakeholder perspectives & 2.88 & 3.88 & 1.0 \\
\hline $\begin{array}{l}\text { 8/Understand how social and economic aspects of public policies influence a business and vice } \\
\text { versa }\end{array}$ & 3.04 & 4.08 & 1.04 \\
\hline \multicolumn{4}{|l|}{ Factor 5: GBC for Theoretical Modeling of Business Phenomena } \\
\hline 3/Apply contemporary business models/flow diagrams to solve business issues & 2.85 & 3.64 & 0.79 \\
\hline 2/Design/conduct research of a business issue employing quantitative analytical skills & 3.08 & 4.10 & 1.02 \\
\hline 1/Apply abstract theories to practical business issues using critical thinking skills & 2.85 & 4.19 & 1.34 \\
\hline \multicolumn{4}{|l|}{ Factor 6: GBC for Evolved Awareness of Social Norms } \\
\hline 4/Function in multi-functional/disciplinary teams building consensus and making compromises & 3.74 & 4.46 & 0.72 \\
\hline $\begin{array}{l}\text { 6/Understand the ethical issues associated with the social responsibility of a business in a global } \\
\text { context }\end{array}$ & 3.30 & 4.02 & 0.72 \\
\hline
\end{tabular}


As shown in Table 1, students rated 11 out of their 24 specific competencies (i.e. items 2, 4, 6, 8. 11. 12, 15, 17, 16, 23, and 24) as appropriate (i.e. with a mean in excess of 3). In contrast, students rated 24 out of 24 specific competencies as appropriate after taking strategy/capstone course as a result of their improved general mastery of business phenomena. In order to gain a better understanding of the student perception scores in terms of this improvement, a factor analysis was performed on student competency gap scores (i.e. column 4 in Table 1).

\section{FACTOR AND MANOVA ANALYSES OF STUDENT COMPETENCY GAPS}

A factor analysis was conducted in order to identify the underlying constructs (i.e. GBCs) by grouping similar specific competency gaps fulfilled in the strategy/capstone course. The underlying factors were determined through the principal component procedure of the SPSS/PC software package. Each of the competency gap items was analyzed by using the principal component procedure to extract the factors followed by a varimax rotation. The criterion value for item inclusion was a loading of .40. Items with loadings on more than one factor were included only in interpretations of the factor with the highest loading. The factor analysis yielded a six-factor solution with eigen values greater than 1 . The selected items and their loadings on the six factors are shown in Table 2.

Table 2: Selected Competency Items And Their Loadings On The Six Factors

\begin{tabular}{|c|c|c|c|c|c|c|}
\hline \multirow[t]{2}{*}{ Items } & \multicolumn{4}{|c|}{ Factors } & \multirow[b]{2}{*}{5} & \multirow[b]{2}{*}{6} \\
\hline & 1 & 2 & 3 & 4 & & \\
\hline 12 & .714 & & & & & \\
\hline 5 & .688 & & & & & \\
\hline 7 & .642 & & & & & \\
\hline 20 & .581 & & & & & \\
\hline 21 & .529 & & & & & \\
\hline 22 & .502 & & & & & \\
\hline 9 & & .681 & & & & \\
\hline 11 & & .668 & & & & \\
\hline 10 & & .542 & & & & \\
\hline 23 & & .532 & & & & \\
\hline 17 & & .524 & & & & \\
\hline 19 & & & .663 & & & \\
\hline 24 & & & .656 & & & \\
\hline 15 & & & .636 & & & \\
\hline 16 & & & .531 & & & \\
\hline 13 & & & & .713 & & \\
\hline 18 & & & & .697 & & \\
\hline 14 & & & & .551 & & \\
\hline 8 & & & & .495 & & \\
\hline 3 & & & & & .760 & \\
\hline 2 & & & & & .693 & \\
\hline 1 & & & & & .502 & \\
\hline 4 & & & & & & .698 \\
\hline 6 & & & & & & .623 \\
\hline
\end{tabular}

The six-factor solution accounted for $62.2 \%$ of the variance. Factor 1 , reflecting student GBC to interpret macro environment, consisted of six items, accounting for $33.02 \%$ of the variance and had an alpha coefficient of .83. Factor 2, reflecting student GBC to communicate of alternatives supported by data, accounted for $8.6 \%$ of the variance, consisted of five items, and had an alpha coefficient of .78. Factor 3, reflecting student GBC for planning and analysis, accounted for $5.96 \%$ of the variance, consisted of four items and had an alpha coefficient of .72. Factor 4, reflecting student GBC to analyze hard data and assess economic impact, accounted for $5.62 \%$ of the variance, consisted of four items, and had an alpha coefficient of .69. Factor 5, reflecting student GBC to apply theoretical 
modeling of business phenomena, accounted for $4.91 \%$ of the variance and had an alpha coefficient of .71. Factor 6 , reflecting student GBC for evolved awareness of social norms, accounted for $4.47 \%$ of the variance, consisted of two items and had an alpha coefficient of .41.

A multivariate analysis of variance (MANOVA) for all six factors (i.e. dependent variables) was used to test for the effect across the following independent/demographic variables: gender, age, major, expected grade in class, full or part-time work status, and grade point average (i.e. GPA). If any effect were found to be statistically significant at the $\mathrm{p}<.05$ level, univariate analysis of variance would be conducted to find the factor(s) contributing to the multivariate significance. Post hoc analysis (multiple comparison) could then be computed to determine the location of the differences (if any) between the groups (if more than two groups). The descriptive statistics illustrating MANOVA analysis for each of the six factors are provided in Table 3.

Table 3: Six Factor Reliability Results

\begin{tabular}{lccc} 
Factor/Name of Factor & \% Variance & \# Items in factor & Reliability \\
\hline $\begin{array}{l}\text { 1. Macro understanding } \\
\text { 2. Communication of }\end{array} \quad 33.02$ & 6 & .8327 \\
$\quad$ alternatives and data & 8.57 & 5 & .7747 \\
3. Planning and analysis & 5.592 & & .7235 \\
4. Analysis and understanding of & 5.619 & 4 & .6891 \\
$\quad$ hard data and economic impact & & 4 & .7079 \\
5. Theoretical modeling & 4.908 & 3 & .4038 \\
6. Awareness of social norms & 4.470 & 2 & \\
\hline
\end{tabular}

MANOVA results revealed significant differences among the major categories on the dependent variables (i.e. general business competencies - GBCs), Wilk’s Lambda $=.734, \mathrm{~F}(30,598)=1.6, \mathrm{p}=.024$. Analysis of variance (ANOVA) was conducted on each dependent variable as a follow-up test to MANOVA. Major category differences were significant for factor 4 - student GBC to analyze hard data and assess economic impact, F $(5,154)=3.742$, $\mathrm{p}=$.003. The Bonferroni Post Hoc analysis revealed that the mean score of this GBC (i.e. factor 4) for accounting major students differed significantly from of that for marketing major students at the .03 level. Also, the mean score for this factor 4 for students in finance major differed significantly from that for student in marketing major at the .02 level. Table 4 presents means and standard deviations for factor 4 for all majors in the business program.

Table 4: Means And Standard Deviations For Factor 4 GBC To Analyze Hard Data And Assess Economic Impact By Major

\begin{tabular}{lllll} 
Major & Mean & SD & N & Mean diff. with mkt./S.E. \\
\hline Accounting & .375 & .339 & 10 & $-.64(.21)^{*}$ \\
Economics & .556 & .497 & 9 & $-.46(.22)$ \\
Finance & .600 & .552 & 45 & $-.42(.13)^{*}$ \\
Information & & & \\
$\quad$ Systems & .750 & .518 & 22 & $-.27(.16)$ \\
Management & .942 & .642 & 36 & $-.07(.14)$ \\
Marketing & 1.019 & .710 & 38 & -- \\
*Significant at the .05 level & & & & \\
\hline
\end{tabular}

The results shown in Table 4 indicate that students in accounting and finance majors entered the strategy class with a higher level of competence for analyzing hard data and assessing the resulting economic impact than did students in marketing major. As a result, students in accounting and finance majors did not "grow" intellectually in this area while learning in the strategy course at the same high rate as the students in marketing major did. These 
significant differences were still found when making between-subject comparisons in spite of the small sample size of the accounting major group. It is very likely that these differences reflect the heavy emphasis on data-driven analysis in the core accounting and finance courses of the business programs, which contrasts the emphasis on verbal explanations in the core marketing courses. Therefore, it may be inferred form the results shown in Table 4 that the gradient of the learning curve for marketing majors in the strategy course is higher relative to this GBC than that for the accounting and finance majors.

In addition, MANOVA revealed marginally significant differences on the dependent variables (the six factors - student GBCs) among the GPA-interval categories, Wilks Lambda $=.843, \mathrm{~F}(18,424)=1.46, \mathrm{p}=.09$. Analysis of variance (ANOVA) indicated that the GPA-interval category differences were significant for factor 1 - student GBC to interpret macro environment, $\mathrm{F}(3,155)=3.38, \mathrm{p}=.019$. The post hoc analysis revealed that the mean score of this factor 1 for the 4-3.5 GPA-interval category differs significantly from that for the 3.5-3.0 category. Table 5 shows means and standard deviations for the factor 1 for each GPA-interval category.

Table 5: Means And Standard Deviations For Factor 1 (Gbc To Interpret Macro Environment)By Gpa Category

\begin{tabular}{lllll} 
GPA & Mean & SD & N & Mean Diff with 3.5-4.0 group \\
\hline $3.5-4.0$ & .95 & .66 & 38 & -- \\
$3.0-3.5$ & 1.34 & .74 & 71 & $.37(.14)^{*}$ \\
$2.5-3.0$ & .99 & .67 & $.03(.15)$ \\
$2.0-2.5$ & .98 & .69 & 4 & $-.05(.37)$ \\
*The mean difference is significant at the .05 level; $* *$ No other GPA comparisons were significant. \\
\hline
\end{tabular}

The results in Table 5 indicate that the highest GPA group had a significantly higher level of understanding of the macro environmental issues surrounding business strategy decisions. The higher mean score of the 3.0 - 3.5 group reflects a higher levels of learning about macro business issues for this group than that experienced by the other three groups. No other significant GPA differences were found when making across group comparisons. In addition, further analysis using MANOVA indicated that no difference at the .05 level was found between gender, age, expected grade in the strategy class, and work/employment status.

\section{IMPLICATIONS OF FINDINGS FOR BUSINESS PROGRAM IMPROVEMENT AND FACULTY DEVELOPMENT}

The findings from this research can be particularly useful for administrators and faculty seeking to evaluate the effectiveness of their business programs. As funding continues to be cut in many state universities across the country, these institutions, striving to maintain needed funding levels and to achieve AACSB (re)accreditation, experience a growing pressure to demonstrate effectiveness of their business programs in educating students to meet the needs of the changing knowledge-intensive workplace. Programs that are ineffective will not only inevitably shrink by losing resources but also may be ultimately eliminated. In effect, business colleges must evaluate the performance of their programs in a way that clearly indicates the path to improvement. The method that we have proposed here permits such an insightful evaluation through an examination of student-centered data.

Many of the performance systems employed in universities to date have relied on standard test scores and exit interviews to evaluate the effectiveness of their business programs. In this paper, we show how before and after comparisons of learning can be used to evaluate the general business competencies acquired in a strategy course and ultimately an evaluation of the integrated business knowledge acquired throughout the business program. As the strategy course is the capstone course, many of the tools that are used in the course are grounded in the previously taught core courses that make the foundation of the business program. The method that we have shown here outlines the improved student GBCs beyond the level acquired in the core courses. These important learning areas of general business functioning are captured in factors formed from specific business competencies, which are then tested for specific groups of students across different majors, genders, GPA's and students with work experience in order to 
determine possible variations in the program effectiveness. This analysis permits evaluation to determine if there are some areas of learning (i.e. different competency gaps) specific to student groups (e.g. majors).

For example, we did find in our analysis that marketing students did not possess the same level of understanding when it came to the analysis and understanding of hard data and their use to assess the economic impact (factor 4) that both accounting and finance majors had acquired in the core courses of their business programs. This points to the need for a more concentrated effort in the marketing major to focus on ways in which marketing students can further develop their skills in the data-intensive analysis to assess the economic value created by a firm. This then becomes one targeted area in curriculum development that marketing and strategy faculty can work on together in order to ensure a better learning outcome for marketing majors.

As a result of this cooperative work, marketing faculty can evaluate their course sequencing and course material in order to determine if a more effective means of communicating this skill to their students could be developed. It should be noted here, however, that the method we proposed provides only a starting point for improving program effectiveness. It does not provide the blueprint for program improvement; rather, it gives the faculty an insight and the starting point for concrete discussions on how to improve the effectiveness of their programs.

The findings from the application of the proposed method can also be extremely helpful for the development of individual faculty members teaching the strategy/capstone course. Faculty members can evaluate their "value added" contribution to student competency improvement in each of the areas (i.e. general business competencies or GBC factors) and compare their score with the average of all faculty teaching the strategy course as a means of objective evaluation. It should be noted that some caution should be taken in using this approach. Individual evaluations should be used, rather than a centralized administrative evaluation, so that the findings do not become institutionalized and impinging on academic freedom with administrative dictum as to the "one best method" for content delivery. Individual differences among faculty teaching styles and their content delivery methods often lead to differences in student understanding based on student preferred learning style. For example, some students achieve a higher level of learning when they are involved in computer strategy games, whereas other students learn more from gathering their own data and developing strategies. Therefore, the findings should be strictly used for individual evaluation as to individual effectiveness and not for an administrative decision as to the preferred method of delivery in the classroom.

When evaluating the change in content delivery methods from one semester to another strategy faculty can determine by using the proposed approach if a new method of content delivery is more or less effective than the one that the faculty member had previously used. The bottom line of this continuing improvement effort is that we, as the concerned faculty (along with the administration) seek primarily for the effective means to provide the best education possible for the students in the business program. We want students to grow intellectually in our courses, and we are seeking to provide them with the tools and competencies that they will need master in order to compete effectively in the marketplace. The traditional simplified course evaluation that provides data on if the student liked the course, the books, and the assignments is no more considered appropriate. We need to go beyond the traditional routine to determine specifically if students perceive that they have a set of GBCs demanded in today's marketplace. This sense of competence should provide the students with self-confidence in using the necessary tools for personal and professional growth when pursuing their lifelong learning. Therefore, when we have a group or groups of students that we are not reaching in our content delivery methods, then we need to re-evaluate our methods and our curriculum in order to ensure the effective learning outcomes for our students.

\section{CONCLUSION}

The framework proposed in this paper has been operationalized to conduct an exploratory empirical study of student competencies reflecting general business competencies that students perceive that they have acquired in strategy course and their business school's program. The results obtained from the study indicate the need for changes and improvements in specific areas that can be made to the core and capstone courses, as well as to the curriculum in the college of business in which the study was administered. 
When employing the proposed method, the areas for change and improvements should be assessed with caution due to the perceptual nature of the instrument used in this study. Therefore, as such a change program has significant implications for the institution, the results obtained from this analysis should be scrutinized in conjunction with student evaluations, focus groups and exit interviews in order to re-examine the input competencies for validity.

Also, any understaffing in the departments delivering core and strategy courses should be examined in conjunction with possibly increased enrollment as these factors create a demand for larger sections that impede learning in upper-level courses. Moreover, this type of study should be designed and conducted longitudinally in order to narrow potential directions for change and focus. This would also permit comparison of learning objective accomplishment of larger and smaller sections, as increased enrollment leads to increased sections over time. Finally, the practical utility of the method proposed conceptually and used empirically in this study can guide both faculty and administrators on how to start at the backend from strategy as the cornerstone course to extend and ensure business knowledge integration across core courses. Such a structured approach would maximize students' perceptions of competence upon graduating from the college's business program.

\section{REFERENCES}

1. Apostolou, B. (2002). Outcomes assessment, Journal of Accounting Education, 14(1): 177-197.

2. Atkinson, M., (2001). The Scholarship of Teaching and Learning: Reconceptualizing Scholarship and Transforming the Academy, Social Forces, 79(4): 1217-1230.

3. Brown, S. and Swartz, T. (1989). A gap analysis of professional service quality, Journal of Marketing, 53: 92-98.

4. $\quad$ Carini, R., Kuh, G., and Klein, S. (2006). Student Engagement and Student Learning: Testing the Linkages, Research in Higher Education, 47(1), February: 1-32.

5. Carlile, O. and Jordan, A. (2005). It works in practice but will it work in theory? The theoretical underpinnings of pedagogy. In S. Moore, G. O'Neill, and B. McMullin (Eds.), Emerging Issues in the Practice of University Learning and Teaching. Dublin: AISHE.

6. De Russy, C. (1996). Public Universities Need Rigorous Oversight by Activist Trusties, Chronicle of Higher Education, October 11, 1996: B3-B4.

7. Donnelly, R. and Fitzmaurice, M. (2005). Designing Modules for Learning. In S. Moore, G. O'Neill,and B.McMullin (Eds.), Emerging Issues in the Practice of University Learning and Teaching. Dublin: AISHE.

8. Entwistle, N. (2005). Learning outcomes and ways of thinking across contrasting disciplines and settings in higher education, Curriculum Journal, 16(1), March: 67-82.

9. Glaser, R. (1990). The Reemergence of Learning Theory within Instructional Research, American Psychologist, 45: 29

10. Graham, S. and Cockriel, I. (1997). A factor structure for social and personal development outcomes in college, NASPA Journal, 34(3): 199-216.

11. Hartenian, L., Schellinger, M., and Frederickson, P. (2001). Creation and assessment of an integrated business course: One college's experience, Journal of Education for Business, January/February: 149-159.

12. Heady, R. and Smith, M. (2000). Business policy case content: A fit with theory and practice? Journal of Education for Business, January/February, 138-141.

13. Michlitsch, J. and Wright Sidde, M. (2002). Assessing student learning outcomes: A comparative study of techniques used in business school disciplines, Journal of Education for Business, January/February, 125130.

14. Mitchell, A. (2006). Introduction to Rubrics: An Assessment Tool to Save Grading Time, Convey Effective Feedback and Promote Student Learning, Journal of College Student Development, 47 (3), May/June: 352355.

15. Novicevic, M. and Buckley, M. (2001). How to Prepare the NeXt Generation Graduates for Contemporary Knowledge-Intensive Workplace, Performance Improvement Quarterly, 14 (2): 125-144.

16. Novicevic, M., Harvey, M., Buckley, M., and Elfessi, A. (2002). Developing Timescape perspective for Educational Delivery, International Journal of Educational Management, (forthcoming).

17. Phar, S. (2000). Foundational considerations for establishing an integrated business common core curriculum, Journal of Education for Business, September/October, 20-23. 
18. Pharr, S., Morris, J., Stover, D., Byers, C., and Reyes, M. (1997). The execution and evaluation of an integrated business common core curriculum, The Journal of General Education, 47(2), 166-182.

19. Slack, N. (1994). The importance-performance matrix as a determinant of improvement priority, International Journal of Operations \& Production Management, 14(5), 59-75.

20. Remenyi, D. and Money, A. (1991). A user-satisfaction approach to IS effectiveness measurement, Journal of Information technology, 6: 162-175.

21. Stover, D., Morris, J., Pharr, S., Byers, C., and Reyes, M., (1997). Breaking down the silo: Attaining an integrated business common core, American Business Review, 15(2), 1-11.

22. The Chronicle of Higher Education (1998). Earned degrees conferred by U.S. institutions 1995-96, November 13, p. A41.

23. Wren, D., Buckley, M., and Michaelson L. (1994). The theory/applications balance in management pedagogy: Where do we stand? Journal of Management, 20, 141-157. 
NOTES 